\title{
Qualidade da Forragem e Participação Relativa na Produção de Matéria Seca de Diferentes Frações de Cultivares de Capim-Elefante (Pennisetum purpureum Schumach.)
}

\author{
Francisco Carlos Deschamps ${ }^{1}$, Cláudio José Freixieiro Alves de Brito ${ }^{2}$
}

\begin{abstract}
RESUMO - A digestão das forragens é determinada por fatores químicos e anatômicos, os quais são afetados pelo estádio de crescimento da espécie. Como as plantas em crescimento apresentam tecidos diversos em composição e anatomia, torna-se importante conhecer sua participação na produção total de matéria seca, bem como seus níveis de digestão. O objetivo do presente trabalho foi determinar a composição química e a digestibilidade das frações colmo, limbo, quilha e bainha foliar, das regiões apical, mediana e basal, dos cultivares 307-TESTO, 309-AREIA e ROXO de capim-elefante (Pennisetum purpureum Schumach.), após 10 semanas de período de crescimento. O cv. AREIA apresentou porte mais elevado com lâminas e bainhas foliares mais curtas, o que acabou acarretando menor participação destas frações no peso seco total. Observou-se que as frações apresentaram teor de lignina, proteína e digestibilidade distintos. O colmo da região basal e a quilha são as frações que mais comprometem a qualidade do capim-elefante, principalmente pelo alto grau de lignificação destas partes. No mesmo estádio de crescimento, poucas diferenças foram observadas entre os cultivares. Foi possível observar que o cv. AREIA apresentou melhor qualidade, já que foram maiores os valores de digestibilidade e proteína bruta do limbo, da quilha e da bainha. A fração mais restritiva para a qualidade da forrageira, em termos de participação e valor nutricional, foi o colmo seguido pela quilha.
\end{abstract}

Palavras-chave: digestibilidade, forragens, lignina, parede celular, ruminantes

\section{Forage Quality and Relative Participation in Dry Matter of Different Fractions of Elephantgrass Cultivars (Pennisetum purpureum Schumach.)}

\begin{abstract}
The digestion of forages is determined by chemical and anatomical factors, which are affected by the growing stage of species. As the growing plants show a variety of tissues in anatomy and composition, it's important to determine their relative participation in total dry matter production, as well their digestion rates. The aim of this paper was to determine the digestibility and chemical composition of leaf fractions (limbo, keel, sheath), as well as of the upper, median and lower part of stems of three elephant grass (Pennisetum purpureum Schumach.) cultivars (307-TESTO, 309-AREIA and ROXO). The plants were harvested with ten weeks of age for leaf and stem fractions separation. The AREIA cultivar was taller than the others with shorter stems and sheaths, which resulted in reduced contribution of these parts in the total dry weight. The several fractions showed different protein, lignin and digestibility rates. The mature lower part of stem and keel are the portions responsible for decreasing elephant grass quality. The contribution of fractions as well the lignification and digestibility levels showed little difference among the cultivars at the same growing stage. The cultivar AREIA showed the best quality, due to higher digestibility and protein values of the leaves. Stem and keel were the main barriers to digestion of elephant grass tissues.
\end{abstract}

Key Words: cell wall, digestibility, forage, lignin, ruminants

\section{Introdução}

O capim-elefante é uma forrageira bastante utilizada para alimentação de bovinos, tanto de corte quanto para a produção de leite. Mesmo apresentando grande potencial produtivo, sua forte produção estacional e a redução do valor nutritivo que acompanha o crescimento das plantas, impõe algumas restrições quanto a sua utilização e manejo (SALERNO et al., 1990). A maturação das plantas vem acompanhada do espessamento e da lignificação da parede celular, estando ambos relacionados à redução na digestibilidade do material (ALVES DE BRITO et al., 1999; WILSON, 1997). Estudos histológicos permitiram observar que, com o desenvolvimento do capim-elefante, a quilha e o colmo são as frações da planta em que o espessamento e a lignificação da parede celular são mais pronunciados (ALVES DE BRITO et al., 1999). Além disso, os autores relataram que estas estruturas são áreas de reduzida

\footnotetext{
${ }^{1}$ Médico Veterinário, Doutor em Bioquímica, Pesquisador, EPAGRI S.A./UNIVALI. Cx. Postal 277, 88.301-970, Itajaí, SC, Brasil. E.mail: xicodsc@hotmail.com. Autor para correspondência.

2 Eng ${ }^{\circ}$-Agrônomo, Doutor em Botânica, Professor Titular, UNIANDRADE. Cx. Postal623, 80.011-970, Curitiba, PR, Brasil. E.mail: cjbrito@hotmail.com
} 
degradação pelo ambiente ruminal. Como os tecidos são diversos, várias estruturas anatômicas apresentaram diferentes graus de degradação pela biota ruminal. Isto afeta a digestibilidade do material como um todo, conforme sugerido por WILKINS (1972), HANNA et al. (1973), AKIN (1979) e WILSON (1993, 1997). Deve ser considerado que os estudos histológicos levam em consideração a área de tecido, o que necessariamente não implica em correspondência com o peso seco total da forragem. Isto pode significar que o comprometimento causado pela presença de frações com baixo potencial de degradação será determinado pela participação de cada uma delas no peso seco total.

O objetivo do presente trabalho foi determinar a participação no peso seco total, a composição bromatológica e a digestibilidade do colmo e das folhas (limbo, quilha e bainha), coletados em três regiões da planta (apical, mediana e basal), de três cultivares de capim-elefante (Pennisetum purpureum Schumach.), ao longo de uma estação de crescimento.

\section{Material e Métodos}

Os três cultivares de capim-elefante ( $P$. purpureum Schumach.), Epagri-307 TESTO, Epagri309-AREIA e ROXO, utilizados no presente estudo, encontravam-se estabelecidos na Estação Experimental da EPAGRI S/A em Itajaí - SC (26054'28'S, 4839'43"W, 5 m.s.m.), em parcelas de $10 \mathrm{~m}$ x $10 \mathrm{~m}$. Dez semanas após o corte de uniformização, realizado em $26 / 11 / 96$, foram selecionadas as plantas em um delineamento em blocos ao acaso, com cinco repetições sendo retiradas oito plantas de cada parcela (rep.). Destas plantas foram retiradas frações constituídas de colmos e folhas, sendo estas subdivididas em limbo (asas), quilha (nervura central) e bainha foliar. As plantas foram divididas em três regiões, denominadas de apical, mediana e basal. Para o estabelecimento dos limites destas regiões, tomou-se o colmo como referência. Uma vez tendo sido as folhas separadas manualmente do colmo, este foi dividido ao meio, denominando-se a fração mais inferior de basal e a porção superior de mediana. Estes dois segmentos (mediano e basal), ficaram constituídos de folhas (limbo, quilha e bainha) e de colmos, enquanto a região denominada de apical, constituiu-se somente de folhas. As folhas mortas, presentes na região basal, não foram subdivididas e constituíram outra amostra. A separação da quilha, que no capim-elefante é bastante pronunciada, foi feita com auxílio de uma lâmina de inox, buscando-se a posição de inserção do limbo na quilha. Após esta separação, o material foi seco em estufa de circulação forçada a $55^{\circ} \mathrm{C}$ e, posteriormente, moído em moinho tipo Wiley com peneira de $2 \mathrm{~mm}$ para a digestão in situ e de $1 \mathrm{~mm}$ para as análises químicas. A proteína bruta foi determinada pelo método Kjelhdahl - semi-micro $(\mathrm{N} * 6,25)$ e a lignina pelo método descrito por THEANDER e WESTERLUND (1986) e HATFIELD et al. (1994). Foi adotada a técnica do saco de náilon, com tempo de incubação fixado em 48 horas, para os ensaios de digestão ruminal, usando-se três bovinos adultos da raça Holandesa dotados de cânula ruminal.

\section{Resultados e Discussão}

$\mathrm{Na}$ Tabela 1 encontram-se os dados morfométricos dos cultivares estudados de capimelefante. Em relação aos outros cultivares, o cv. AREIA apresenta porte mais elevado, com as folhas da região apical estando em menor número e com menor comprimento. A bainha foliar também é mais curta, porém o colmo é mais longo, com maior número de nós na região mediana. O menor comprimento das lâminas e bainhas foliares do cv. AREIA influenciou a participação destas frações em relação ao peso seco total (Tabela 2).

Com base nos valores de digestibilidade e teor de lignina das frações, observa-se que o período de crescimento de dez semanas limitou a discriminação entre os cultivares (Tabela 2). Resultados semelhantes foram relatados por ALVES DE BRITO et al. (1999), ao tentarem comparar estes cultivares sob aspectos anatômicos. Diferenças mais claras foram observadas nos aspectos morfológicos (Tabela 1), os quais são mais evidentes nos estádios iniciais de crescimento (DESCHAMPS, 1999). Portanto, a tentativa de caracterizar cultivares por diferenças anatômicas e/ou químicas pode resultar em interpretações distintas, já que estas características são dependentes do estádio de crescimento.

No presente trabalho, considerou-se a planta como um sistema dinâmico em que tecidos novos e maduros contribuem para a composição da estrutura. Assim, a parte apical da planta apresenta tecidos bastante jovens, com folhas recém expandidas e entrenós em processo de alongamento. Na região mediana, encontraram-se folhas desenvolvidas, maduras, e na região basal, folhas 
Tabela 1 - Características morfométricas de três cultivares de capim-elefante aos 70 dias após corte de emparelhamento ${ }^{1}$ Table 1 - Morphometric characters of three elephantgrass cultivars 70 days after mowing

\section{Cultivar}

Parâmetros

307 TESTO

309 AREIA

ROXO

Parameters

Altura total da planta $(\mathrm{cm})$

$178 \pm 5,3^{\mathrm{b}}$

$196 \pm 11,0^{\mathrm{a}}$

$191 \pm 6,8^{\mathrm{a}}$

Total plant height

$\mathrm{N}^{\mathrm{o}}$ de folhas

Number of leaves

Região apical

Apical region

Região mediana

Median region

Região basal

Basal region

$\mathrm{N}^{\mathrm{o}}$ de folhas mortas região basal

Number of dead leaves on basal region

Comprimento lâmina foliar (cm)

Leaf blade length

Região apical

Apical region

Região mediana

Median region

Região basal

Basal region

Largura da lâmina foliar $(\mathrm{cm})$

Leaf blade width

Região apical

Apical region

Região mediana

Median region

Região basal

$7,2 \pm 0,7^{b}$

$4,1 \pm 0,6^{b}$

$2,9 \pm 0,6^{\mathrm{a}}$

$2,7 \pm 0,7^{\mathrm{a}}$

$103 \pm 14,9^{\mathrm{a}}$

$101 \pm 6,1^{\mathrm{a}}$

$85 \pm 11,4^{b}$

$89 \pm 6,5^{\mathrm{a}}$

$76 \pm 9,7^{\mathrm{a}}$

$4,5 \pm 0,6^{\mathrm{a}}$

$3,7 \pm 0,4^{b}$

$3,7 \pm 0,6^{\mathrm{b}}$

$3,5 \pm 0,7^{\mathrm{a}}$

$3,4 \pm 0,3^{\mathrm{a}}$

$3,1 \pm 0,5^{\mathrm{a}}$

$2,9 \pm 0,4^{\mathrm{a}}$

$2,3 \pm 0,4^{\mathrm{a}}$

Comprimento da bainha $(\mathrm{cm})$

Leaf blade width

Região apical

Apical region

Região mediana

Median region

Região basal

Basal region

Comprimento do colmo $(\mathrm{cm})$

Stem length

Diâmetro do colmo (mm)

Stem diameter

Região mediana

Median region

Região basal

Basal region

$\mathrm{N}^{\mathrm{O}}$ de nós do colmo

Number of nodes

Região mediana

Median region

Região basal

Basal region

$\begin{array}{ccc}21,2 \pm 2,1^{\mathrm{a}} & 18,4 \pm 4,4^{\mathrm{b}} & 25,0 \pm 3,7^{\mathrm{a}} \\ 20,9 \pm 1,5^{\mathrm{a}} & 16,4 \pm 1,7^{\mathrm{b}} & 22,6 \pm 3,1^{\mathrm{a}} \\ - & 18,0 \pm 3,1^{\mathrm{b}} & 24,5 \pm 5,0^{\mathrm{a}} \\ 94 \pm 2,2^{\mathrm{b}} & 124 \pm 4,7^{\mathrm{a}} & 101 \pm 5,5^{\mathrm{b}}\end{array}$

$1,3 \pm 0,14^{\mathrm{a}}$

$1,3 \pm 0,19^{\mathrm{a}}$

$1,4 \pm 0,09^{\mathrm{a}}$

$1,4 \pm 0,33^{\mathrm{a}}$

$1,3 \pm 0,11^{\mathrm{a}}$

$1,4 \pm 0,21^{\mathrm{a}}$

$3,4 \pm 0,7^{b}$

$4,9 \pm 0,6^{\mathrm{a}}$

$3,9 \pm 0,3^{b}$

$4,0 \pm 0,5^{b}$

$4,6 \pm 1,3^{\mathrm{a}}$

$5,0 \pm 0,5^{\mathrm{a}}$

1 Médias (8 repetições) seguidas de mesma letra na linha não diferem pelo teste Duncan $(p>0,05)$.

1 Average (8 replicates) followed by the same letter, within a row, do not differ by Duncan test ( $p>.05)$. 
já senescentes e entrenós totalmente alongados. Desse modo, pode-se considerar que os tecidos de cada uma dessas regiões apresentam características próprias a cada fase de crescimento da planta.

A partir dos resultados descritos (Tabelas 1 e 2), observa-se que a lignificação aumenta e a digestibilidade diminui a partir da região apical em direção à basal. Isto se deve à presença de tecidos mais jovens na região apical, ainda em processo de diferenciação celular, enquanto na basal grande parte de peso seco é determinada pelo colmo, já bastante maduro e lignificado. É possível sugerir, então, que as plantas encerram em si um gradiente de qualidade, já que neste estádio existem folhas e colmos com vários graus de maturação. Isto pode ser comprovado ao se compararem os índices de digestibilidade e lignificação das folhas na região apical com as demais, e do colmo mediano com o basal (Tabela 2). Nas folhas, a quilha é a fração menos digerida, apresentando digestibilidade média em torno de $50 \%$. Em grande parte este resultado pode ser associado ao seu maior grau de lignificação (Tabela 2). Entretanto, a importância da quilha na qualidade forrageira do capim-elefante não pode ser desconsiderada, porque a contribuição da quilha no peso seco total pode ser considerada elevada, já que representa cerca de $9 \%$ no cv. AREIA e próximo a $13 \%$ nos demais. Observa-se ainda que, na fração quilha, os valores de digestibilidade e de teor de lignina não apresentaram variação acentuada entre as regiões da planta. Em parte, isto pode estar associado à função de sustentação exercida pela quilha, desde a expansão da lâmina foliar. Neste caso, parece que a resistência do tecido fica garantida com a deposição precoce de lignina ao longo do tecido.

A presença de tecidos com diferentes estádios de maturação e, portanto, com diferente susceptibilidade à digestão, ajuda a compreender a redução na digestibilidade que gramíneas tropicais apresentam ao longo da maturação, em acordo com as sugestões de AKIN (1979), WILSON (1997) e ALVES DE BRITO et al. (1999). Pode-se considerar que a limitação final será determinada pela participação de cada fração na composição total da planta. Somando-se o peso do colmo basal e da quilha em todas as folhas, chega-se a cerca de $40 \%$ do peso total. Estas frações apresentam pouco mais de $40 \%$ de digestibilidade, o que pode ser considerado baixo para adequada alimentação de ruminantes. Forragens com baixa digestibilidade tendem a permanecer maior tempo no rúmen, exigindo maior tempo de ruminação. Isto implica em menor consumo e menor disponibilidade de nutrientes para a produção (WILSON, 1997).

A bainha foliar apresenta elevado nível de digestibilidade quando em estádio jovem, ao contrário do que é observado em estádio maduro. Por outro lado, pode ser considerada pequena a participação da bainha no peso seco total, afetando pouco a digestibilidade final do capim-elefante. Em estudos envolvendo a determinação da área de degradação dos tecidos da bainha dos mesmos cultivares, ALVES DE BRITO et al. (1999) determinaram ser esta fração de grande potencial de digestão. Entretanto, os autores verificaram que, a partir de oito semanas de crescimento, parte da área digerida foi devida à presença do aerênquima. Esta denominação é dada às lacunas formadas a partir da destruição das células do parênquima, as quais favorecem a disseminação dos microorganismos ruminais.

Quanto ao teor de proteína bruta, observa-se na Tabela 2 que todas as frações apresentaram redução no sentido apical-basal. Tal redução é bastante acentuada na bainha e no colmo e este fenômeno é típico de ocorrer com o envelhecimento das plantas (DESCHAMPS, 1999). Deve ser considerado que a restrição na disponibilidade de nitrogênio afeta a ação dos microrganismos no rúmen. $\mathrm{O}$ desequilíbrio de nutrientes no ambiente ruminal afetará, portanto, a digestão dos alimentos com implicações para o desempenho animal.

Observando-se os três cultivares quanto à digestibilidade e ao teor de proteína bruta, constatase que o cv. AREIA apresentou os melhores níveis. Isto pode representar uma vantagem qualitativa deste cultivar em relação aos demais. Com exceção do colmo, as demais frações do cv. AREIA apresentaram parâmetros de qualidade superiores às apresentadas pelos demais cultivares. Já o cv. TESTO foi o que apresentou os parâmetros mais restritivos, sugerindo assim qualidade inferior. Nesse caso, os resultados da caracterização química e da digestibilidade seguiram a mesma tendência relatada por ALVES DE BRITO et al. (1999), quando mensuraram as áreas de tecidos lignificados nesses mesmos cultivares.

Pode-se considerar que a determinação de parâmetros químicos e histológicos pode ser útil em programas de seleção de cultivares na busca por materiais que apresentem melhor arranjo nos tecidos e menor grau de lignificação, com maior digestibilidade. Como exemplo, a seleção de cultivares de capimelefante com porte mais baixo e lâminas foliares mas 
Tabela 2 - Distribuição (\%) no peso seco total das diversas frações do colmo e folhas de três cultivares de capim-elefante, com correspondentes níveis de digestibilidade, lignina e proteína bruta ${ }^{1}$

Table 2 - Total dry weight distribution (\%) of several leaf and stems fractions of three elephantgrass cultivars, with digestibility, lignin and protein levels associated

\begin{tabular}{|c|c|c|c|c|c|c|c|c|c|}
\hline \multirow[t]{2}{*}{$\begin{array}{l}\text { Parâmetro } \\
\text { Parameter }\end{array}$} & \multicolumn{3}{|c|}{$\begin{array}{c}\text { Apical } \\
\text { Apical region }\end{array}$} & \multicolumn{3}{|c|}{$\begin{array}{c}\text { Mediana } \\
\text { Median region }\end{array}$} & \multicolumn{3}{|c|}{$\begin{array}{c}\text { Basal } \\
\text { Basal region }\end{array}$} \\
\hline & TESTO & AREIA & ROXO & TESTO & AREIA & ROXO & TESTO & AREIA & $\mathrm{ROXO}$ \\
\hline & \multicolumn{9}{|c|}{ Limbo (Limbo) } \\
\hline $\begin{array}{l}\text { Peso seco } \\
\text { Dry weight }\end{array}$ & 21,1 & 13,6 & 20,3 & 8,1 & 13,4 & 9,4 & - & 2,2 & 1,7 \\
\hline $\begin{array}{l}\text { Digestibilidade } \\
\text { Digestibility }\end{array}$ & $71,4^{\mathrm{a}}$ & $75,0^{\mathrm{a}}$ & $74,5^{\mathrm{a}}$ & $63,3^{\mathrm{ab}}$ & $67,8^{\mathrm{abc}}$ & $68,7^{a b c}$ & - & $65,5^{\mathrm{bc}}$ & $60,2^{c}$ \\
\hline $\begin{array}{l}\text { Lignina } \\
\text { Lignin }\end{array}$ & $16,7^{\mathrm{c}}$ & $17,1^{\mathrm{c}}$ & $16,8^{\mathrm{c}}$ & $22,2^{\mathrm{a}}$ & $19,8^{b}$ & $22,4^{\mathrm{a}}$ & - & $21,1^{\mathrm{a}}$ & $22,0^{\mathrm{a}}$ \\
\hline $\begin{array}{l}\text { Proteína bruta } \\
\text { Crude protein }\end{array}$ & $12,5^{\mathrm{c}}$ & $15,4^{\mathrm{a}}$ & $14,9^{\mathrm{a}}$ & $12,1^{\mathrm{c}}$ & $13,7^{\mathrm{b}}$ & $14,0^{b}$ & - & $11,8^{\mathrm{c}}$ & $11,0^{\mathrm{d}}$ \\
\hline & & \multicolumn{8}{|c|}{ Quilha (Keel) } \\
\hline $\begin{array}{l}\text { Peso } \operatorname{seco}^{\mathrm{a}} \\
\text { Dry weight }\end{array}$ & 8,0 & 3,9 & 8,2 & 4,8 & 4,7 & 4,7 & - & 0,8 & 0,8 \\
\hline $\begin{array}{l}\text { Digestibilidade } \\
\text { Digestibility }\end{array}$ & $44,2^{\mathrm{ab}}$ & $48,6^{\mathrm{a}}$ & $49,5^{\mathrm{a}}$ & $36,6^{\mathrm{c}}$ & $41,0^{\mathrm{bc}}$ & $46,9^{\mathrm{ab}}$ & - & $51,3^{\mathrm{a}}$ & $48,4^{\mathrm{a}}$ \\
\hline $\begin{array}{l}\text { Lignina } \\
\text { Lignin }\end{array}$ & $19,6^{\mathrm{ab}}$ & $18,6^{\mathrm{bc}}$ & $19,3^{a b c}$ & $20,4^{\mathrm{a}}$ & $19,3^{a b c}$ & $20,5^{\mathrm{a}}$ & - & $18,1^{\mathrm{c}}$ & $18,8^{b c}$ \\
\hline $\begin{array}{l}\text { Proteína bruta } \\
\text { Crude protein }\end{array}$ & $3,8^{\mathrm{e}}$ & $6,2^{\mathrm{a}}$ & $5,7^{b}$ & $3,6^{\mathrm{e}}$ & $5,0^{\mathrm{c}}$ & $4,2^{\mathrm{d}}$ & - & $4,5^{\mathrm{d}}$ & $4,3^{\mathrm{d}}$ \\
\hline & & \multicolumn{8}{|c|}{ Bainha (Leaf sheath) } \\
\hline $\begin{array}{l}\text { Peso seco } \\
\text { Dry weight }\end{array}$ & 4,9 & 2,7 & 4,5 & 6,6 & 6,3 & 6,8 & - & 1,6 & 1,7 \\
\hline $\begin{array}{l}\text { Digestibilidade } \\
\text { Digestibility }\end{array}$ & $62,7^{\mathrm{a}}$ & $66,8^{\mathrm{a}}$ & $63,0^{\mathrm{a}}$ & $48,4^{\mathrm{bc}}$ & $48,9^{b c}$ & $53,6^{\mathrm{b}}$ & - & $49,7^{\mathrm{bc}}$ & $50,7^{\mathrm{bc}}$ \\
\hline $\begin{array}{l}\text { Lignina } \\
\text { Lignin }\end{array}$ & $14,9^{\mathrm{b}}$ & $14,3^{b}$ & $15,1^{b}$ & $18,8^{\mathrm{a}}$ & $18,9^{\mathrm{a}}$ & $18,3^{\mathrm{a}}$ & - & $18,8^{\mathrm{a}}$ & $18,5^{\mathrm{a}}$ \\
\hline $\begin{array}{l}\text { Proteína bruta } \\
\text { Crude protein }\end{array}$ & $7,3^{b}$ & $9,5^{\mathrm{a}}$ & $7,6^{\mathrm{b}}$ & $3,5^{\mathrm{c}}$ & $3,6^{\mathrm{c}}$ & $3,5^{\mathrm{c}}$ & - & $2,8^{\mathrm{d}}$ & $3,2^{d}$ \\
\hline & & \multicolumn{8}{|c|}{ Colmo (Stem) } \\
\hline $\begin{array}{l}\text { Peso } \operatorname{seco}^{\mathrm{a}} \\
\text { Dry weight }\end{array}$ & - & - & - & 14,7 & 16,0 & 13,0 & 25,6 & 30,7 & 24,7 \\
\hline $\begin{array}{l}\text { Digestibilidade } \\
\text { Digestibility }\end{array}$ & - & - & - & $65,4^{\mathrm{a}}$ & $54,4^{\mathrm{b}}$ & $68,1^{\mathrm{a}}$ & $42,6^{\mathrm{c}}$ & $33,9^{d}$ & $47,2^{\mathrm{c}}$ \\
\hline $\begin{array}{l}\text { Lignina } \\
\text { Lignin }\end{array}$ & - & - & - & $13,6^{\mathrm{cd}}$ & $14,7^{\mathrm{c}}$ & $12,4^{\mathrm{d}}$ & $17,5^{\mathrm{b}}$ & $18,9^{\mathrm{a}}$ & $16,8^{\mathrm{c}}$ \\
\hline $\begin{array}{l}\text { Proteína bruta } \\
\text { Crude protein }\end{array}$ & - & - & - & $4,4 \mathrm{~b}$ & $4,5^{\mathrm{c}}$ & $8,1^{\mathrm{a}}$ & $2,3 \mathrm{~d}$ & $3,7^{\mathrm{c}}$ & $3,9^{\mathrm{c}}$ \\
\hline & & \multicolumn{8}{|c|}{ Folha morta (Dead leaf) } \\
\hline $\begin{array}{l}\text { Peso } \operatorname{seco}^{\mathrm{a}} \\
\text { Dry weight }\end{array}$ & - & - & - & - & - & - & 3,3 & 2,5 & 1,7 \\
\hline $\begin{array}{l}\text { Digestibilidade } \\
\text { Digestibility }\end{array}$ & - & - & - & - & - & - & $44,9^{\mathrm{a}}$ & $45,2^{\mathrm{a}}$ & $48,3^{\mathrm{a}}$ \\
\hline $\begin{array}{l}\text { Lignina } \\
\text { Lignin }\end{array}$ & - & - & - & - & - & - & $22,5^{\mathrm{a}}$ & $23,1^{\mathrm{a}}$ & $20,7^{\mathrm{a}}$ \\
\hline $\begin{array}{l}\text { Proteína bruta } \\
\text { Crude protein }\end{array}$ & - & - & - & - & - & - & $3,4^{\mathrm{a}}$ & $4,6^{\mathrm{a}}$ & $4,5^{\mathrm{a}}$ \\
\hline \multicolumn{10}{|c|}{ Bainha morta (Dead leaf sheath) } \\
\hline $\begin{array}{l}\text { Peso } \operatorname{seco}^{\mathrm{a}} \\
\text { Dry weight }\end{array}$ & - & - & - & - & - & - & 2,9 & 1,6 & 2,1 \\
\hline $\begin{array}{l}\text { Digestibilidade } \\
\text { Digestibility }\end{array}$ & - & - & - & - & - & - & $43,0^{\mathrm{a}}$ & $33,4^{\mathrm{b}}$ & $38,6^{\mathrm{a}}$ \\
\hline $\begin{array}{l}\text { Lignina } \\
\text { Lignin }\end{array}$ & - & - & - & - & - & - & $20,6^{\mathrm{b}}$ & $23,2^{\mathrm{a}}$ & $21,2^{\mathrm{b}}$ \\
\hline $\begin{array}{l}\text { Proteína bruta } \\
\text { Crude protein }\end{array}$ & - & - & - & - & - & - & $2,7^{b}$ & $3,7^{\mathrm{a}}$ & $3,5^{\mathrm{a}}$ \\
\hline
\end{tabular}

1 Médias seguidas de mesma letra, na linha, não diferem pelo teste Duncan ( $p>0,05)$.

1 Average followed by the same letter, within a row, do not differ by the Duncan test ( $p>0.05)$.

a Participação da fração em relação ao peso seco total (Participation of each fraction over total dry weight).

b Digestibilidade in situ (48 h) da MS (In situ dry matter digestibility [48 h]). 
curtas e estreitas reduziria a participação das frações colmo e quilha, os quais apresentaram-se bastante restritivos nutricionalmente.

Já em termos de manejo, a utilização de plantas mais jovens reduz a participação do colmo na composição do peso seco total, amenizando os efeitos negativos da lignina sobre a digestão final. Esse manejo não afetaria a quilha, que compromete a qualidade das folhas mesmo nas partes jovens da planta.

No presente trabalho, foi possível comprovar que diversas frações que compõem o capim-elefante apresentam distintas características químicas e de digestão. Mesmo tecidos considerados de alta digestibilidade, como as folhas, apresentam partes que comprometem sua qualidade, como a quilha. É interessante observar que o teor de lignina não é o único fator a afetar negativamente a digestibilidade. A quilha, o limbo e mesmo o colmo basal apresentam teores de lignina elevados e com pequenas diferenças numéricas. Entretanto, a digestibilidade do limbo é consideravelmente superior à quilha e ao colmo (Tabela 2). Isto sugere que a composição da lignina ou seus precursores, ou mesmo a sua interação com os carboidratos da parede celula, sejam distintos nestes tecidos, afetando de forma diferenciada a digestão dos tecidos.

\section{Conclusões}

Ao longo de uma estação de crescimento, os cultivares de capim-elefante estudados apresentaram frações com diferentes estádios de lignificação que afetam a digestibilidade. Considerando a participação e o valor nutritivo de cada fração, a quilha e o colmo maduro (basal) são as frações que mais comprometem a qualidade desta forrageira.

O grau de lignificação e a digestibilidade das frações pouco diferem entre os três cultivares, indicando apenas que o cv. AREIA apresentou níveis mais elevados de digestibilidade e proteína bruta em todas as frações, com exceção do colmo. $\mathrm{O}$ cv. AREIA destacou-se também, por apresentar porte mais elevado, com lâminas e bainhas foliares mais curtas.

\section{Referências Bibliográficas}

AKIN, D.E. 1979. Microscopic evaluation of forage digestion by rumen microorganisms - A review.J. Anim. Sci., 48:701-710.

ALVES DE BRITO, C.J.F., RODELLA, R.A., DESCHAMPS, F.C. et al. 1999. Anatomia quantitativa e degradação in vitro de tecidos em cultivares de capim-elefante (Pennisetum purpureum Schumach.). Rev. bras. zootec., 28(2):223-229.

DESCHAMPS, F.C. Perfil fenológico de três ecotipos de capimelefante (Pennisetum purpureum Schum.). In: REUNIÃO ANUAL DA SOCIEDADE BRASILEIRA DE ZOOTECNIA, 34, Juiz de Fora, 1997. Anais... Juiz de Fora: SBZ, 1997. p.62-64.

DESCHAMPS, F.C. 1999. Implicações do período de crescimento na composição química e digestão dos tecidos de cultivares de capim elefante. Rev. bras. zootec., 28(6):1178-1189.

HANNA, W.W., MONSON, W.G., BURTON, G.W. 1973. Histological examination of fresh forage leaves after in vitro digestion. Crop Sci., 13:98-102.

HATFIELD, R.D., JUNG, H.J.G., RALPH, J. et al. 1994. A comparison of the insoluble residues produced by klason lignin and acid detergent lignin procedures. J. Sci. Food Agric. 65:51-58.

SALERNO, A.R., VETTERLE, C.P., DESCHAMPS, F.C. et al. 1990. Gramineas forrageiras estivais perenes no Baixo Vale do Itajaí. Florianópolis: EMPASC. 99p. (EMPASC, Boletim Técnico, 49).

THEANDER, O., WESTERLUND, E. 1986. Studies on dietary fiber. 3. Improved procedures for analysis of dietary fiber. J. Agric. Food Chem., 34:330-336.

WILKINS, R.J. 1972. The potential digestibility of cellulose in grasses and its relationship with chemical and anatomical parameters. J. Agric. Sci., 78:457-464.

WILSON, J.R. 1993. Organization of forage plant tissues. In: JUNG, H.G, BUXTON, D.R., HATFIELD, R.D. et al. (Eds.)Forage cell wall structure and digestibility. Madison: ASA/CSSA/SSSA.p.1-32.

WILSON, J.R. 1997. Structural and anatomical traits of forage influencing their nutritive value for ruminants. In: SIMPÓSIO INTERNACIONAL SOBRE PRODUÇÃO ANIMAL EM PASTEJO, 1997, Viçosa. Anais... Viçosa: DZO-UFV, 1997. p.173-208. 